\title{
Risk Factors for Surgical Recurrence after lleocolic Resection of Crohn's Disease
}

\author{
Jonathan T. Unkart, B.A. ${ }^{1}$, Lauren Anderson, B.A. ${ }^{1}$, Ellen Li, M.D., Ph.D. ${ }^{1}$, Candace Miller, \\ M.A. ${ }^{2}$, Yan Yan, Ph.D. ${ }^{2,3}$, C. Charles Gu, Ph.D. ${ }^{3}$, Jiajing Chen, M.P.H. ${ }^{1}$, Christian D. Stone, \\ M.D., M.P.H. ${ }^{1}$, Steven Hunt, M.D. ${ }^{2}$, and David W. Dietz, M.D. ${ }^{4}$ \\ 1 Department of Medicine, Division of Gastroenterology, Washington University School of Medicine, St. \\ Louis, Missouri \\ 2Department of Surgery, Section of Colon and Rectal Surgery, Washington University School of Medicine, \\ St. Louis, Missouri \\ 3Division of Biostatistics, Washington University School of Medicine, St. Louis, Missouri \\ 4Department of Colorectal Surgery, Cleveland Clinic, Cleveland, Ohio
}

\section{Abstract}

PURPOSE-We evaluated the effect of potential clinical factors on surgical recurrence of ileal Crohn's disease after initial ileocolic resection.

METHODS-One hundred seventy-six patients with ileal Crohn's disease who underwent an ileocolic resection with anastomosis were identified from our database. The outcome of interest was time from first to second ileocolic resection. Survival analysis was used to assess the significance of the Montreal phenotype classification, smoking habit, a family history of inflammatory bowel disease and other clinical variables.

RESULTS-In our final Cox model, a family history of inflammatory bowel disease (hazard ratio 2.24, 95 percent confidence interval 1.16-4.30, $P=0.016$ ), smoking at time of initial ileocolic resection (hazard ratio 2.08, 95 percent confidence interval 1.11-3.91, $P=0.023$ ) was associated with an increased risk of a second ileocolic resection while postoperative prescription of immunomodulators (hazard ratio $0.40,95$ percent confidence interval $0.18-0.88, P=0.022$ ) was associated with a decreased risk of a second ileocolic resection.

CONCLUSIONS-Both a family history of inflammatory bowel disease and smoking at the time of the initial ileocolic resection are associated with an increased risk of a second ileocolic resection. Postoperative prescription of immunomodulators is associated with a reduced risk of surgical recurrence. This study supports the concept that both genetic and environmental factors influence the risk of surgical recurrence of ileal Crohn's disease.

\section{Keywords}

Crohn's disease; Ileocolic resection; Postoperative recurrence

Address of correspondence: David W. Dietz, M.D., Department of Colorectal Surgery, Cleveland Clinic, 9500 Euclid Ave., Desk A-30, Cleveland, Ohio 44195. E-mail: dietzd2@ccf.org.

Read at the meeting of The American Society of Colon and Rectal Surgeons, St. Louis, Missouri, June 2 to 7, 2007. 


\section{INTRODUCTION}

Crohn's disease (CD) is a chronic inflammatory bowel disease (IBD) that affects any part of the gastrointestinal tract and frequently affects the terminal ileum. Although many patients are initially treated medically, approximately 80 percent of patients with ileal CD will eventually undergo resection of diseased bowel. ${ }^{1,2}$ Operative indications include failed medical therapy, perforation, obstruction, hemorrhage, and neoplasia. ${ }^{3}$ Unfortunately, surgery is rarely curative. Endoscopic evidence of recurrent disease in the neoterminal ileum is often observed within months after resection. ${ }^{4}$ In a population-based study of 908 patients that underwent surgery for ileocecal disease, 43 percent report symptoms consistent with clinical relapse after a median of 6.8 years. ${ }^{2}$ The cumulative risk of surgical recurrence in 146 patients who underwent surgery for ileocolic disease at the Cleveland Clinic is 50 percent after 14 years. ${ }^{5}$ Multiple resections of diseased bowel may lead to the development of short bowel syndrome.

The aim of this largely retrospective study is to identify clinical variables that influence the risk of postoperative recurrence of ileal $\mathrm{CD}$. Identifying clinical variables associated with increased risk of postoperative recurrence has clinical implications with respect to optimizing $\mathrm{CD}$ therapy for each individual. For example, a patient found to be at extremely high risk for early recurrence may be considered for more potent or experimental chemoprophylaxis agents (e.g., infliximab) where the risk:benefit ratio might be otherwise deemed too high. In addition, some risk factors may be directly amenable to modification (i.e., smoking).

$\mathrm{CD}$ is a heterogeneous disease with multiple phenotypic classifications. In this study we have adopted the Montreal classification of $\mathrm{CD}$, in order to determine whether classification by age of diagnosis, disease location or disease behavior influences the risk of postoperative recurrence. ${ }^{6}$ Host genetic factors and environmental factors have been implicated in the pathogenesis of CD. ${ }^{7-10}$ Cigarette smoking is the best described of the environmental factors. A number of studies have shown that smoking increases the risk of recurrent CD. ${ }^{11-16} \mathrm{We}$ therefore examined the association of a family history of IBD and smoking habits with the risk of surgical recurrence. Finally, changes in surgical and postoperative medical management have occurred over the past two decades that could potentially impact the time to surgical recurrence of ileal CD. These include the introduction of laparoscopic surgery, 17,18 and the use of 5-aminosalicylic acid (5-ASA) compounds, immunomodulators (purine analogs and methotrexate), and/or biologics directed against tumor necrosis factor $\alpha$ (anti-TNF $\alpha$ ) during the postoperative period. ${ }^{19-21} \mathrm{We}$ consequently also included the surgical approach and postoperative prescription of medications as potentially important clinical variables.

\section{METHODS}

Patients

This study was approved by the Washington University in St. Louis Human Research Protection Office. One hundred seventy-six adult CD patients who had undergone an ICR with anastomosis were identified from the Washington University Digestive Diseases Research Core Center (DDRCC) Clinical Database. This database includes 654 CD patients that were recruited in a consecutive fashion during inpatient and outpatient visits to physicians within the Section of Colon and Rectal Surgery and the Division of Gastroenterology at the Washington University Medical Center (WUMC) between April 1, 2005, and October 30, 2007. Patients that were unwilling or unable to give informed consent were excluded from the Washington University DDRCC Clinical Database. The medical charts of all patients in the database that reported undergoing an ICR were reviewed and the history of previous ICR was confirmed by review of the original records - particularly the pathology and operative report. Permission was prospectively obtained from each patient enrolled in the database by the Washington University DDRCC Clinical Component to obtain records of previous surgeries 
if these records were not included in their medical record. Patients for whom we were unable to obtain the original records documenting the initial ICR and patients that underwent an ileostomy were excluded from the study. The patients included in the database have been followed longitudinally on a yearly basis by reviewing their medical records and by directly contacting the patients.

\section{Clinical Variables}

Gender and race were recorded as reported by the patients. The Montreal classification 6 was used to phenotype the patients (Table 1). The patients were classified with respect to age of diagnosis as (A1) $\leq 16 \mathrm{yr}$, (A2) 17-40 y, (A3) >40. Disease location was recorded at the time of the initial ICR. All of the patients had terminal ileal disease so patients were either classified as (L1) ileal disease with and without disease limited to the cecum or (L3) ileal disease with disease of the colon beyond the cecum. Upper small bowel disease (L4+) in addition to L1 or L3 is scored as a disease modifier. None of the patients had disease limited to the colon (L2). Disease behavior was recorded at the time of the initial ICR and at the second ICR as (B1) nonstricturing, nonpenetrating, (B2) stricturing, and (B3) penetrating intestinal disease. Perianal fistulizing disease $(\mathrm{p}+)$ was scored separately as a modifier of disease behavior. The presence or absence of a family history of IBD in a first or second-degree relative and a detailed smoking history at the time of the initial ICR and during the postoperative period was scored by reviewing the medical records and interviewing the patient. A smoker at the time of the initial ICR was defined as smoking $\geq 7$ cigarettes per week for at least a year. During the postoperative period patients who stopped smoking for more than a year at the time of followup or at the time of the second resection were categorized as exsmokers. Patients who continued to smoke or began smoking at the time of follow-up or at the time of the second resection were categorized as smokers. The surgical approach was classified as either a laparoscopic-assisted or traditional open midline incision technique. In the vast majority of the cases, the ileocolic anastomosis was constructed using a stapled side-to-side functional end-to-end technique. The time of the initial ICR was recorded as the year of the surgery. The place of surgery was recorded as having taken place at the WUMC or at another facility. Finally, the prescription of 5-ASA compounds, immunomodulators (6-mercaptopurine, azathioprine, and methotrexate), or biologics (e.g., infliximab, adalimumab) during the postoperative period was recorded based on a review of the medical records and interviewing the patient.

\section{Statistical Analysis}

The outcome of interest was time from first ICR (ICR1) to second ICR (ICR2). The KaplanMeier (KM) method was used to estimate survival curves with the log-rank test to test for homogeneity of the survival functions across strata. The strata were defined by the (categorical) clinical variables of interest (described in previous section), including gender, race, age of diagnosis, disease location, UGI disease location modifier, disease behavior, perianal disease behavior modifier, a family history of IBD, smoking at the time of ICR1, smoking during the postoperative period, laparoscopic vs. open surgical approach, place of surgery, postoperative use of 5-ASA products, postoperative use of immunomodulators, postoperative use of biologics directed against TNF $\alpha$. Patients who died $(n=0)$, or were lost to follow-up $(n=5)$, underwent revision of the anastomosis for resection of colonic disease $(n=3)$, underwent surgery for upper gastrointestinal disease $(n=3)$, were all coded as right-censored. The statistical software SPSS 15.0 was used for Kaplan-Meier analysis and for plotting the survival curves. To identify important risk factors with respect of their collective action, Cox proportional hazard model with backward elimination was applied to select the most promising subset of risk factors by multiple regression. In addition to the categorical variables listed above, age of diagnosis, the duration of disease (duration between time of diagnosis and time of ICR1), and age of ICR1 were analyzed as continuous variables. The effect of risk factors on the time to ICR2 was quantified by the hazard ratios (HR) from the final Cox model. A generous significance level 
threshold of 0.15 was used to prevent premature elimination of important risk factors. The PROC TPHREG in the statistical software SAS 9.0 was used for the analysis.

\section{RESULTS}

\section{Montreal Classification of Patients}

The clinical variables for the patients included in this study are summarized in Tables 1 and 2 . Forty percent of the patients were male and 60 percent were female. The patients were predominantly white (93 percent). The majority ( 69 percent) of the patients were diagnosed between the ages of 17 and 40 years. Twelve percent had childhood onset of $C D(\leq 16$ years) and 19 percent were diagnosed as older adults ( $>40$ years). The patients were homogeneous with respect to Montreal classification by disease location, with 85 percent exhibiting disease in the ileocecal region at the time of ICR1. Only 15 percent had disease located distal to the cecum and 6 percent had more proximal small bowel disease that was also present at the time of ICR1. The patients were heterogeneous with respect to Montreal classification by disease behavior. Fifty-four percent of the patients had penetrating disease (fistula, abscess, perforation), 38 percent had stenosing disease and 8 percent had inflammatory (nonstricturing and nonpenetrating disease) at the time of ICR1. Twenty-seven percent of the patients also had perianal disease.

\section{Univariate Analysis of Categorical Clinical Variables}

The median age of the patient at the time of ICR1 was 30 years and the median duration of disease prior to ICR1 was 3 years. The overall time to ICR2 and the effect of categorical variables were analyzed using the Kaplan-Meier method. The results of the log-rank tests for each categorical variable are presented in Table 3 . The overall predicted median time to ICR2 was 12 years. Univariate analysis identified two clinical variables associated with a decreased predicted time to ICR2, a family history of IBD, and smoking at the time of ICR1 (Figs. 1 and 2). One clinical variable, postoperative prescription of an immunomodulator (Fig. 3), was associated with an increased predicted time to ICR2.

\section{Cox Proportional Hazards Model for Surgical Recurrence after Initial ICR}

A stepwise backward elimination method was used to arrive at the final Cox proportional hazards model shown in Table 4. In this model, a family history of IBD and smoking at time of ICR1 were significantly associated $(P=0.016-0.023)$ with an increased risk of ICR2, while the postoperative prescription of immunomodulators was significantly associated with a decreased risk of ICR2 $(P=0.022)$. The postoperative prescription of anti-TNF $\alpha$ biologics was also included in the model but its association with an increased risk of ICR2 did not reach significance $(P=0.13)$. The $P$ value for the final model was $\sim 0.003$.

\section{DISCUSSION}

The major aim of this largely retrospective study was to identify the clinical variables that potentially impact the risk of postoperative recurrence of $\mathrm{CD}$. In order to restrict the $\mathrm{CD}$ phenotype, this analysis focused on surgical recurrence of ileal disease as measured by the time between ICR1 and ICR2. We observed no effect of the Montreal classifications with respect to age of diagnosis, disease location, or disease behavior in this study. However, relatively few patients with childhood onset of $\mathrm{CD}$ and disease location extending beyond the ileocecal region were included in this study. We observed no effect of disease behavior at the time of ICR1 on the risk of ICR2. This may be because disease behavior is not a static phenotype. ${ }^{22} \mathrm{We}$ noted that 32 of 53 patients that underwent more than one ICR exhibited a different disease behavior at ICR2 than they did at ICR1. The exclusion of patients that had an ileostomy placed at the 
time of ICR 1 in this study, may have excluded patients with very severe penetrating disease (e.g., peritonitis).

Three clinical variables associated with an altered risk of undergoing ICR 2 were identified by univariate analysis and confirmed by multivariate regression analysis. The first was a family history of IBD. Only two prior studies have investigated the relationship between family history of IBD and surgical recurrence. ${ }^{15,23}$ Ryan et al. reported that a family history increased the risk of perianastomotic recurrence in patients with ileocecal disease. ${ }^{15}$ Chardavoyne et al. found no effect but analyzed the risk of surgical recurrence after both large and small bowel resections. ${ }^{23}$ This observation supports the concept that genetic factors affect the risk of postoperative recurrence.

We confirmed multiple previous studies that smoking at the time of ICR1 was associated with an increased risk of ICR2, but did not detect any effect of postoperative smoking habit on the risk of ICR2. Only eight smokers at the time of ICR1 discontinued smoking immediately after surgery, making it difficult to assess whether smoking cessation reduces the risk of ICR2.

Smoking has been associated with disease location in the small bowel, but the molecular basis for how smoking impacts CD pathogenesis is not well understood. ${ }^{24}$

Postoperative prescription of immunomodulators, (e.g., 6-mercaptopurine, azathioprine, and methotrexate), was associated with a decreased risk of repeat ICR. This observation supports the concept that the postoperative maintenance therapy with these agents may prevent and/or delay postoperative recurrence of CD after ICR 1. ${ }^{19-21}$ Multiple regression analysis showed borderline association of postoperative prescription of anti-TNF $\alpha$ biologics with an increased risk of second ICR. There are theoretic concerns that rapid mucosal healing with these biologics could result in excessive scar formation. ${ }^{25}$ This could in turn lead to the formation of strictures, development of small bowel obstruction, and the need for surgical intervention. In this largely retrospective study, however, this observation may reflect treatment selection bias in prescribing the medication to CD patients who had already developed stricturing disease. ${ }^{26}$

\section{CONCLUSIONS}

Both a family history of IBD and smoking at the time of the ICR1 are associated with an increased risk of undergoing ICR2. Postoperative prescription of immunomodulators is associated with a reduced risk of surgical recurrence. This study supports the concept that both genetic and environmental factors influence the risk of surgical recurrence of ileal CD.

\section{Acknowledgements}

This authors thank the patients who have contributed their medical information to the Digestive Diseases Research Core Center (DDRCC) Clinical Database, Michael Lewis and Drs. Elisa Birnbaum, James Fleshman, Ira Kodner, Jennifer Lowney, Matthew Mutch in the Section of Colon and Rectal Surgery, Drs. Matthew Ciorba, Ray Clouse, Nicholas Davidson, Dayna Early, Chandra Prakash, Deborah Rubin and William Stenson in the Division of Gastroenterology at Washington University, and Dr. Robert Rothbaum in the Division of Pediatric Gastroenterology and Nutrition at Washington University for their help and support in recruiting patients, the community gastroenterologists including Drs. Barry Abramson, Marc Bernstein, Paul Buse, David Cort, Steve Fern, John J. Kelly, Carl Lyss, Robert Shuman, Eric Thyssen, Janet Todorczuk, David Walden, Michele Woodley, Leonard Weinstock, Michael Zerega for their help and support in recruiting patients, and Dr. David Alpers for helpful discussions and suggestions in preparing this manuscript.

This work was supported in part by NIH grant P30 DK52574 (Li), Barnes Jewish Foundation Grant 00434-0805-01 (Dietz/Hunt), Johnson and Johnson Translational Seed Award (Li). L.A. was supported by T35 DK074375. 


\section{References}

1. Farmer RG, Whelan G, Fazio VW. Long-term follow-up of patients with CD. Relationship between the clinical pattern and prognosis. Gastroenterology 1985;88:1818-25. [PubMed: 3922845]

2. Bernell O, Lapidus A, Hellers G. Risk factors for surgery and recurrence in 907 patients with primary ileocaecal CD. Br J Surg 2000;87:1697-701. [PubMed: 11122187]

3. Strong SA, Koltun WA, Hyman NH, Buie WD. Standards Practice Task Force of the American Society of Colon and Rectal Surgeons. Practice parameters for the surgical management of Crohn's disease. Dis Colon Rectum 2007;50:1735-46. [PubMed: 17690937]

4. Rutgeerts P, Geboes K, Vantrappen G, Beyls J, Kerremans R, Hiele M. Predictability of the postoperative course of CD. Gastroenterology 1990;99:956-63. [PubMed: 2394349]

5. Lock MR, Farmer RG, Fazio VW, Jagelman DG, Lavery IC, Weakley FL. Recurrence and reoperation for CD. N Engl J Med 1981;304:1586-88. [PubMed: 7231504]

6. Satsangi J, Silverberg MS, Vermeire S, Colombel JF. The Montreal classification of inflammatory bowel disease: controversies, consensus, and implications. Gut 2006;55:749-53. [PubMed: 16698746]

7. Goyette P, Labbé C, Trinh TT, Xavier RJ, Rioux JD. Molecular pathogenesis of inflammatory bowel disease: genotypes, phenotypes and personalized medicine. Ann Med 2007;39:177-99. [PubMed: 17457716]

8. Cho JH, Weaver CT. The genetics of inflammatory bowel disease. Gastroenterology 2007;133:132739. [PubMed: 17919503]

9. Xavier RJ, Podolsky DK. Unravelling the pathogenesis of inflammatory bowel disease. Nature 2007;448:427-34. [PubMed: 17653185]

10. Loftus EV Jr. Clinical epidemiology of inflammatory bowel disease: incidence, prevalence, and environmental influences. Gastroenterology 2004;126:1504-17. [PubMed: 15168363]

11. Sutherland LR, Ramcharan S, Bryant H, Fick G. Effects of cigarette smoking on recurrence of CD. Gastroenterology 1990;98:1123-8. [PubMed: 2323505]

12. Cottone M, Rosselli M, Orlando A, et al. Smoking habits and recurrence in CD. Gastroenterology 1994;106:643-8. [PubMed: 8119535]

13. Moskovitz D, McLeod RS, Greenberg GR, Cohen Z. Operative and environmental risk factors for recurrence of CD. Int J Colorectal Dis 1999;14:224-6. [PubMed: 10647631]

14. Yamamoto T, Keighley MR. The association of cigarette smoking with a high risk of recurrence after ileocolonic resection for ileocecal CD. Surg Today 1999;29:579-80. [PubMed: 10385380]

15. Ryan WR, Allan RN, Yamamoto T, Keighley MR. CD patients who quit smoking have a reduced risk of reoperation for recurrence. Am J Surg 2004;187:219-25. [PubMed: 14769308]

16. Kane SV, Flicker M, Katz-Nelson F. Tobacco use is associated with accelerated clinical recurrence of CD after surgically induced remission. J Clin Gastroenterol 2005;39:32-5. [PubMed: 15599207]

17. Lowney JK, Dietz DW, Birnbaum EH, Kodner IJ, Mutch MG, Fleshman JW. Is there any difference in recurrence rates in laparoscopic ICR for CD compared with conventional surgery? A long-term, follow-up study. Dis Colon Rectum 2006;49:58-63. [PubMed: 16328612]

18. Tan JJ, Tjandra JJ. Laparoscopic surgery for CD: a meta-analysis. Dis Colon Rectum 2007;50:57685. [PubMed: 17380366]

19. Hanauer SB, Korelitz BI, Rutgeerts P, et al. Postoperative maintenance of CD remission with 6mercaptopurine, mesalamine, or placebo: a 2-year trial. Gastroenterology 2004;127:723-9. [PubMed: 15362027]

20. Ardizzone S, Maconi G, Sampietro GM, et al. Azathioprine and mesalamine for prevention of relapse after conservative surgery for CD. Gastroenterology 2004;127:730-40. [PubMed: 15362028]

21. Vermeire S, van Assche G, Rutgeerts P. Altering the natural history of CD-evidence for and against current therapies. Aliment Pharmacol Ther 2007;25:3-12. [PubMed: 17229216]

22. Louis E, Collard A, Oger AF, Degroote E, Aboul Nasr El, Yafi FA, Belaiche J. Behaviour of CD according to the Vienna classification: changing pattern over the course of the disease. Gut 2001;49:777-82. [PubMed: 11709511]

23. Chardavoyne R, Flint GW, Pollack S, Wise L. Factors affecting recurrence following resection for CD. Dis Colon Rectum 1986;29:495-502. [PubMed: 3731965] 
24. Aldhous MC, Drummond HE, Anderson N, Smith LA, Arnott ID, Satsangi J. Does cigarette smoking influence the phenotype of CD? Analysis using the Montreal classification. Am J Gastroenterol 2007;102:577-88. [PubMed: 17338736]

25. Burke JP, Mulsow JJ, O'Keane C, Docherty NG, Watson RW, O'Connell PR. Fibrogenesis in CD. Am J Gastroenterol 2007;102:439-48. [PubMed: 17156147]

26. Lichtenstein GR, Olson A, Travers S, et al. Factors associated with the development of intestinal strictures or obstructions in patients with CD. Am J Gastroenterol 2006;101:1030-8. [PubMed: 16606351] 


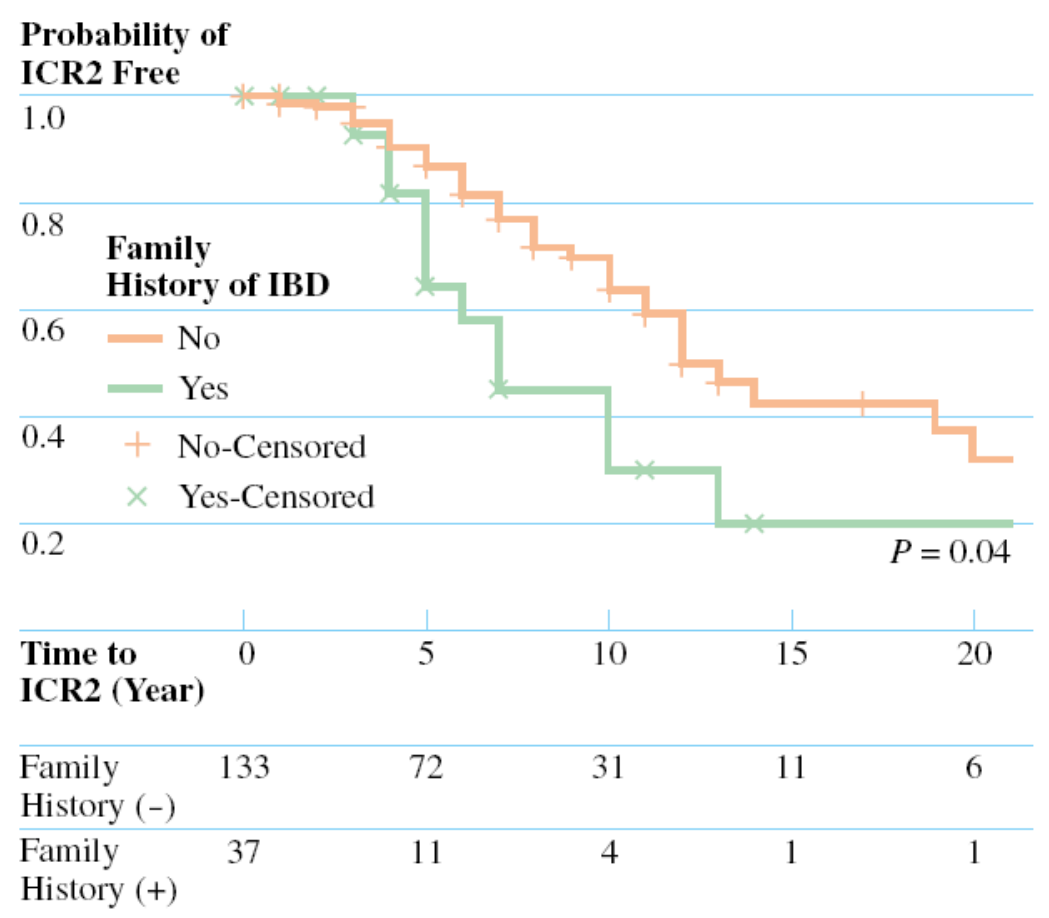

FIGURE 1.

Comparison of the cumulative ICR2 free rates between (solid line) patients without a family history of inflammatory bowel disease (IBD) and with a family history of IBD (dotted line), together with the $P$ value from the log-rank test. The number of patients at risk in each strata are displayed at the bottom. 


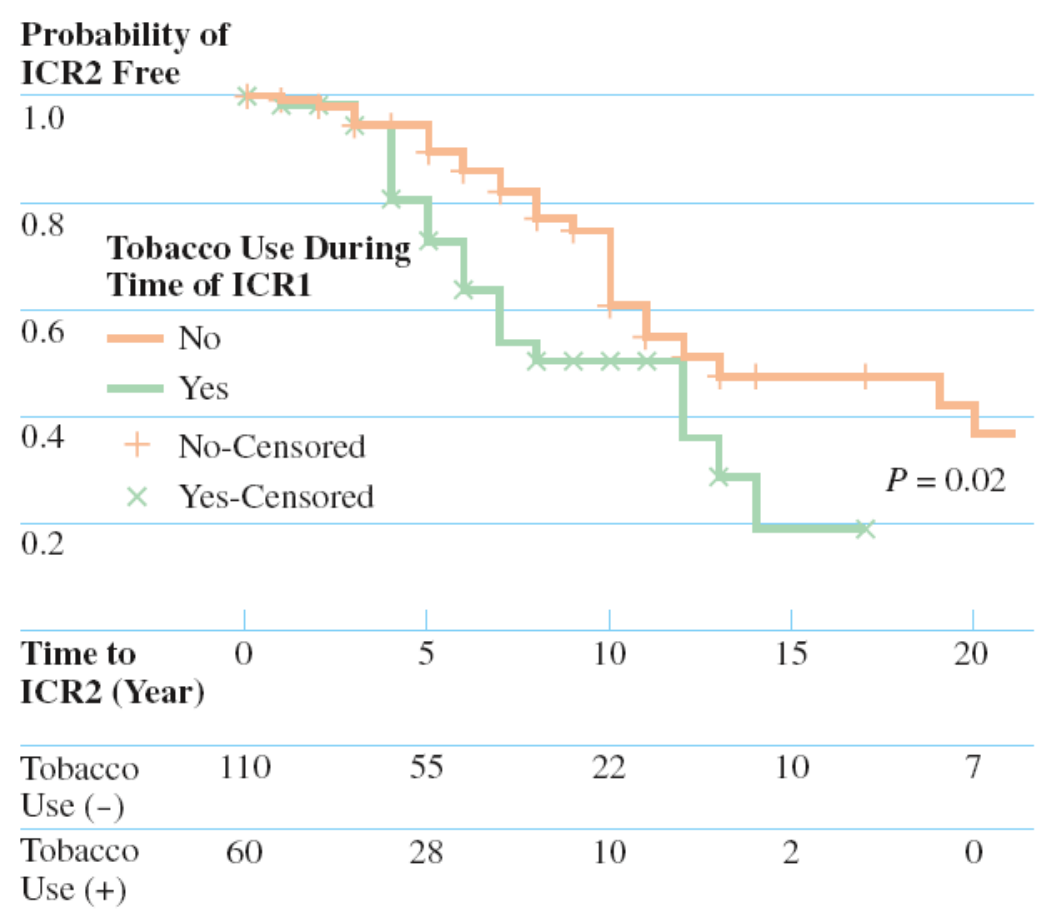

FIGURE 2.

Comparison of the cumulative ICR2 free rates between (solid line) nontobacco users at initial ICR with tobacco users at initial ICR (dotted line), together with the $P$ value from the log-rank test. The number of patients at risk in each strata are displayed at the bottom. 


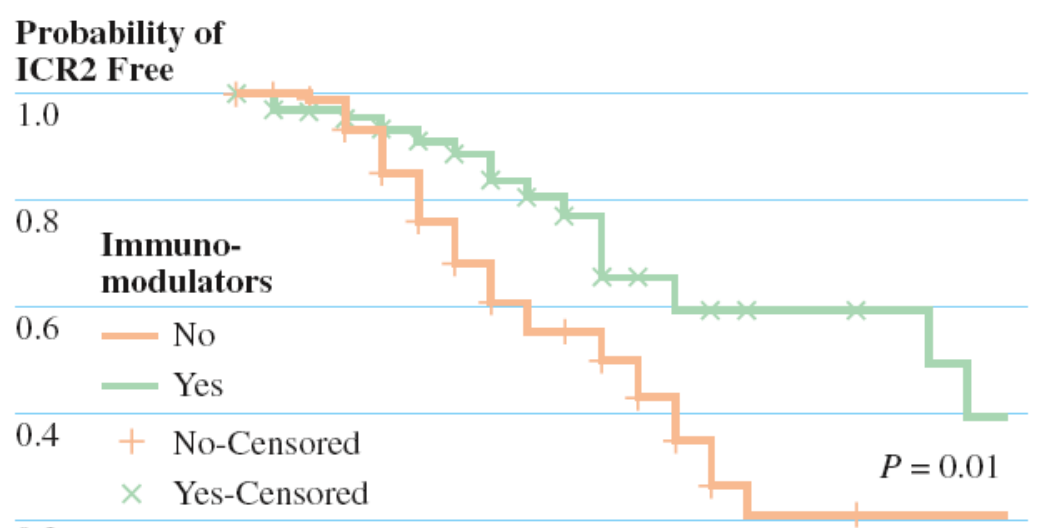

0.2

\begin{tabular}{lccccc}
\hline $\begin{array}{l}\text { Time to } \\
\text { ICR2 (Year) }\end{array}$ & 0 & 5 & 10 & 15 & 20 \\
\hline $\begin{array}{l}\text { Immun. } \\
\text { Use (-) }\end{array}$ & 103 & 42 & 18 & 4 & 3 \\
\hline $\begin{array}{l}\text { Immun. } \\
\text { Use (+) }\end{array}$ & 67 & 41 & 17 & 8 & 4 \\
\hline
\end{tabular}

FIGURE 3.

Comparison of the cumulative ICR2 free rates between patients prescribed postoperative immunomodulators (dotted line) and those not prescribed postoperative immunomodulators (solid line), together with the $P$ value from the log-rank test. The number of patients at risk in each strata are displayed at the bottom. 
Patient clinical variables $(n=176)$

Table 1

\begin{tabular}{|c|c|c|}
\hline Clinical variable & \# Patients & Percent \\
\hline \multicolumn{3}{|l|}{ Gender } \\
\hline Male & 70 & $40 \%$ \\
\hline \multicolumn{3}{|l|}{ Race } \\
\hline White & 161 & $91 \%$ \\
\hline Black & 13 & $7 \%$ \\
\hline Hispanic & 1 & $1 \%$ \\
\hline Asian & 1 & $1 \%$ \\
\hline \multicolumn{3}{|l|}{ Age of diagnosis (Montreal classification) } \\
\hline $\mathrm{A} 1 \leq 16$ years & 21 & $12 \%$ \\
\hline A2 $17-40$ years & 121 & $69 \%$ \\
\hline A $3>40$ years & 34 & $19 \%$ \\
\hline \multicolumn{3}{|l|}{ Disease location ICRI (Montreal classification) } \\
\hline L1 ileum \pm cecum & 149 & $85 \%$ \\
\hline L3 ileum \pm colon (beyond cecum) & 27 & $15 \%$ \\
\hline L4 + upper gastrointestinal disease modifier & 10 & $6 \%$ \\
\hline \multicolumn{3}{|l|}{ Disease behavior ICRI (Montreal classification) } \\
\hline B1 inflammatory & 15 & $8 \%$ \\
\hline B2 stenosing & 66 & $38 \%$ \\
\hline B3 penetrating & 95 & $54 \%$ \\
\hline $\mathrm{P}+$ perianal disease modifier & 47 & $27 \%$ \\
\hline \multicolumn{3}{|l|}{ Family history of inflammatory bowel disease } \\
\hline 1 st or $2^{\text {nd }}$ degree relative & 39 & $22 \%$ \\
\hline
\end{tabular}

ICR1, first ICR. 
Patient clinical variables $(n=176)$

\section{Table 2}

\begin{tabular}{|c|c|c|}
\hline Clinical variable & Median or \# patients & Range or \% \\
\hline Median age of ICRI (years) & 30 & Range $12-75$ \\
\hline Median duration of disease prior to ICRI (years) & 3 & Range $0-26$ \\
\hline Median year of ICRI & 2001 & Range $1970-2007$ \\
\hline Patients with \#ICR >2 & 53 & $30 \%$ \\
\hline \multicolumn{3}{|l|}{ Medical center for ICRI } \\
\hline Washington University Medical Center & 126 & $72 \%$ \\
\hline \multicolumn{3}{|l|}{ Surgical approach ICRI } \\
\hline Laparoscopic & 49 & $28 \%$ \\
\hline Converted & 4 & $2 \%$ \\
\hline Open & 123 & $70 \%$ \\
\hline \multicolumn{3}{|l|}{ Smoking habit } \\
\hline Smoker at time of ICR1 & 62 & $35 \%$ \\
\hline Continued smoking after ICR1 & 48 & $27 \%$ \\
\hline Stopped smoking after ICR1 & 14 & $8 \%$ \\
\hline Nonsmoker at time of ICR1 & 114 & $65 \%$ \\
\hline Continued nonsmoker after ICR1 & 109 & $62 \%$ \\
\hline Started smoking after ICR1 & 4 & $2 \%$ \\
\hline Started smoking then stopped after ICR1 & 1 & $1 \%$ \\
\hline \multicolumn{3}{|l|}{ Postoperative medications after ICRI } \\
\hline 5-aminosalicylic acid compounds & 104 & $59 \%$ \\
\hline Immunomodulators & 69 & $39 \%$ \\
\hline Anti-TNF $\alpha$ biologics & 36 & $20 \%$ \\
\hline
\end{tabular}

ICR1, first ICR. 
Table 3

Univariate analysis of categorical clinical variables

\begin{tabular}{lc}
\hline Clinical variable & P value \\
\hline Gender & 0.21 \\
Race & 0.89 \\
Age of diagnosis (A1 $v s$. A2 $v s$. A3, Montreal classification) & 0.11 \\
Disease location at ICR1 (L1 vs. L3, Montreal classification) & 0.37 \\
Upper gastrointestinal modifier at ICR1 (L4 + vs. no L4, Montreal classification) & 0.73 \\
Disease behavior at ICR1 (B1 vs. B2 $v s$. B3, Montreal classification) & 0.43 \\
Perianal disease modifier at ICR1 (p + vs. no p +, Montreal classification) & 0.97 \\
Family history of inflammatory bowel disease & $\mathbf{0 . 0 4}$ \\
$\quad$ Medical center for ICR1 (Washington University Medical Center $v s$. outside hospital) & 0.27 \\
$\quad$ Surgical approach (laparoscopic $v s$. open) & 0.41 \\
Smoking at ICR1 & $\mathbf{0 . 0 2}$ \\
Postoperative smoking & 0.15 \\
$\quad$ Postoperative prescription of 5-aminosalicylic acid compounds & 0.72 \\
Postoperative prescription of immunomodulators & $\mathbf{0 . 0 1}$ \\
$\quad$ Postoperative prescription of anti-TNF $\alpha$ biologics & 0.61 \\
\hline
\end{tabular}

ICR1, first ICR. 
Table 4

Final Cox proportional hazards model $(P=0.003)$ of risk factors for surgical recurrence after ICR1

\begin{tabular}{lccc}
\hline Variable & Model coefficient & HR & 95\% confidence limits \\
\hline Family history of IBD & 0.80 & 2.24 & $1.16-4.30$ \\
Smoking at ICR1 & 0.73 & 2.08 & $1.11-3.91$ \\
Postoperative immunomodulator & -0.92 & 0.40 & $0.18-0.88$ \\
Postoperative anti-TNF $\alpha$ biologics & 0.67 & 1.96 & $0.82-4.70$ \\
ICR1, first ileocolic resection & & & 0.023 \\
IBD, inflammatory bowel disease & & & 0.132 \\
& & & \\
\hline
\end{tabular}

